\title{
Social aspects of sleep disorders among older people
}

\author{
Antonina Ostrowska
}

Instytut Filozofii i Socjologii Polskiej Akademii Nauk

Address for correspondence: Instytut Filozofii i Socjologii Polskiej Akademii Nauk, ul. Nowy Świat 72, 00-330 Warszawa, aostrows@ifispan.waw.pl

\section{Abstract}

The paper is a sociological analysis of the phenomenon of insomnia in older population. The aim is to show the experience of sleep disorders in a social context, i.e. relating them to the socio-economic situation, the quality of life, the frame of mind and the social functioning of seniors. The approach taken is not clinical, which is oriented towards a neurological explanation of the phenomenon, the diagnostics and treatment. Nor is it epidemiological, which generally considers only the demographic features, or characteristics of the state of health, in its analysis of insomnia. The occurrence of insomnia in various European countries and seeking the similarities and dissimilarities in its social correlates will be the subject of further analyses.

\section{Key words: insomnia, older population, sleep disorders, quality of life \\ Stowa kluczowe: bezsenność, starsi Iudzie, zaburzenia snu, jakosść życia}

The occurrence of sleep disorders in European countries was the subject of a question in the European Social Survey (ESS), carried out on representative population samples in 24 European countries in 2015. The results of the study are interesting for the analyses of the appearance of insomnia, both with respect to the broad set of data concerning the psychological functioning of individuals (as potential correlates of the occurrence of sleep disorders) and enabling relevant comparisons between older people and the whole surveyed populations to be made. The results will be the basis for further considerations. The people who stated that they had slept badly, or not at all, in the preceding week were classed as those experiencing sleep disorders. Those aged between of 6580 are regarded as older people. People in this age range constitute about $15 \%$ of the population in various European countries (Eurostat 2016). The analyses exclude the group of the so called 'aged people', over 80 years old, because of the potential disorder of their cognitive function and communication difficulties [1] and because of the small number of such people in the surveyed population samples. In the countries surveyed, there were 28 , 221 people in the group of older people.

What is colloquially described with the collective term insomnia, consists, from the clinical point of view, of vari- ous forms of night sleep disorders: falling asleep disorders, manifesting themselves in many hours of waiting for sleep to occur; disorders during the night in the form of waking, with difficulties in falling asleep again; waking up too early and the impossibility of resuming sleep. The reasons for the different kinds of disorders are diverse - typical of different dysfunctions, they can have either, a transitory, or a chronic, character ${ }^{1}$. Insomnia is one of the symptoms of depression, it also accompanies various somatic illnesses, in particular those which are characterised by complaints of pain [4]. The lack of sleep can be a symptom of an illness, or its cause, and in extreme cases it requires hospitalisation. However, healthy people often suffer from sleep disorders - and there are various causal factors - stress, anxiety and life problems, states of excessive agitation or emotional tension, overstraining of the organism, or an unhealthy lifestyle and the use of stimulants [5]. Nevertheless, irrespective of the reason, sleep disorders, especially if they have a chronic character, cause constant fatigue, a reduction in energy, difficulties with concentration and frequently increased sensitivity and irritation. Sleepless nights lower the possibility of functioning normally [6] and may impair the general quality of life [3].

It is generally known that the problem of insomnia increases with ageing. For this reason, it is mainly older 
people, who constitute a fast growing segment of the population of Europe, who suffer from a lower sense of well-being related to a prolonged lack of sleep, or its poor quality. Therefore, all activities aimed at relieving the ageing processes should take this issue into account. The available information indicates that the phenomenon of sleeplessness increases, especially in women [3], who primarily take sleeping pills and tranquilisers. However, the drugs in the Benzodiazepine group, which are used most frequently, are notorious for their addictive potential [7]. This provides an additional reason to be interested in the methods by which people try to combat the lack of sleep. However, there is little research undertaken into the problem of insomnia to make it possible for its psycho-social correlates to be identified.

The problem of insomnia and the remedies are most often considered in medical categories, however, there are a number of implications of a psychological and social nature [8], and their recognition may contribute to the development of a strategy for good ageing. Not without significance is the identification of the categories of older people in specific "risk groups" prone to insomnia because of various aspects of their social situation and the experienced forms of stress. In this paper, sleep disorders in older people are discussed, primarily from the perspective of the differences in their social situation in selected European countries, which, to various degrees, create the conditions required for good ageing. It is both the question of the place occupied in the social structure of each country and the cultural differences which permeate factors such as age and gender $[9,10]$.

Much concern is given to the study of sleep, and, particularly its disorders, in the United States. The American Academy of the Medicine of Sleep and the National Sleep Foundation conduct studies into the quality of Americans' sleep. However, they are conducted primarily from a medical viewpoint. Studies on the structure and functioning of the brain are dominant in clinical research - they can even be included in the new, brilliantly developing discipline of neuro science. In epidemiological research, the demographic variables, race, data on the state of health and the use of stimulants are usually taken into consideration. Additionally, the occurrence of sleep disorders in various social classes is taken into account in some studies, but the results are not conclusive [11].

Research on the occurrence of insomnia in European countries often considers it as a component of depression. Consequently, in many surveys insomnia appears almost exclusively, only as an indicator of depression. It is similar in Polish research $[12,13]$. However, in worldwide research, complaints about the quality of sleep are reported more often than the estimated indicators of depression [14]. In Poland, according to the National Health Interview Survey, almost one in four has suffered from sleep disorders [15]. Research from 2009 [16] reported that $8 \%$ of the studied group take sleeping pills prescribed by a doctor on a regular basis. However, there is no systematic method which makes it possible to compare and monitor the data over a period of several years, or empirically evaluate the relationship between depres- sion and insomnia. At the same time, foreign research indicates that sleeplessness often occurs irrespective of depression, as a result of difficult experiences and many kinds of stress encountered during the day. According to the estimates of American researchers [17], sleeplessness linked to depression constitutes only about $40 \%$ of the diagnosed cases. An additional limitation to the knowledge of this subject is the selective nature of the populations included in the research. The majority of research on depression or mental health does not include persons aged over 65, or it concentrates solely on the treated (registered) cases. In Poland, the most comprehensive survey of the mental condition of the population [18] conducted in recent years, considers only people in the age range 18-64.

However, the problems of older people's mental health should not be ignored. The PolSenior Study [13] demonstrated that for people over 65 the occurrence of depression was about 10 percentage points higher than in the population aged 55-59, and for people over 80 years of age, it was 16 percentage points higher. It can be estimated that these differences would have been even higher if the frequency of sleeplessness had been compared. Older people are subject to many stressful experiences, including those linked to their socio-economic position, deteriorating state of health, limited access to health and care services, often loneliness, their dependence on others and the diminishing sense of control over their own life. Psychological studies also indicate that they frequently experience fear of old age and the limitations caused by ageing, which disrupt their sense of well-being and satisfaction with life [19]. These experiences, which increase the focus of seniors on themselves and the risks arising from their environment, may loom large in their mind, resulting in sleepless nights. In addition, traumatic events linked with a serious illness, or death of a spouse and widowhood, often play an important role. However, irrespective of the reason for sleep disorders and their connection with biological, psychological and social factors, they create a substantial risk to the well-being of people of more advanced age. Therefore, the quality of sleep, the occurrence of its disorders and the factors shaping them in older people deserve more research attention, however, not only by the medical or clinical sciences, but also by the social sciences. These problems relate to one of the essential aspects of actions needed for healthy ageing and are, therefore, important to the condition of society as a whole.

Sociology researchers in America and Europe devote relatively little attention to this problem. Therefore, there is scant information concerning the social context in which sleep disorders occur, the social factors influencing sleep quality, individual experiences of sleeplessness, or its perceived consequences. However, information concerning the occurrence of sleeplessness recently appeared in the data collected during the SHARE Euro 5 research project [20]. Of the European studies researching sleeplessness in a broader social context, it is worth mentioning Finnish research concerning the link between sleeplessness and mass unemployment at the time of eco- 
nomic recession [21] and British studies of sleep disorders, in the context of a series of variables characterising the social and economic position, the family situation and the specificity of social roles issuing from the distinction of gender roles [22]. The findings indicate that there is a link between the social situation and the experience of sleeplessness and that macro-social factors may play an indirect role. This can be illustrated by the differences in the frequency of sleeplessness among older people in different European countries, which will be the subject of an analysis later in this paper.

The frequency of these declarations for the surveyed populations (adults) and for older people (65-80) is presented in Figure 1.
Generally, differences in the occurrence of sleep disorders for the whole population in various countries can be linked to the influence of many different geographic and socio-cultural factors which, may appear together. They are factors such as the climate, the amount of sunlight, the strength of the stimuli of the technical civilisation and of the "pace of life", the spread of addictions, political conflicts, economic crises and the general level and quality of life. Not without importance are the specific circumstances such as access to tranquilisers and sleeping pills, which help to solve the problem. When analysing sleeplessness and the general frame of mind in the populations of older people, it is necessary to consider their social situation in the country of residence, the

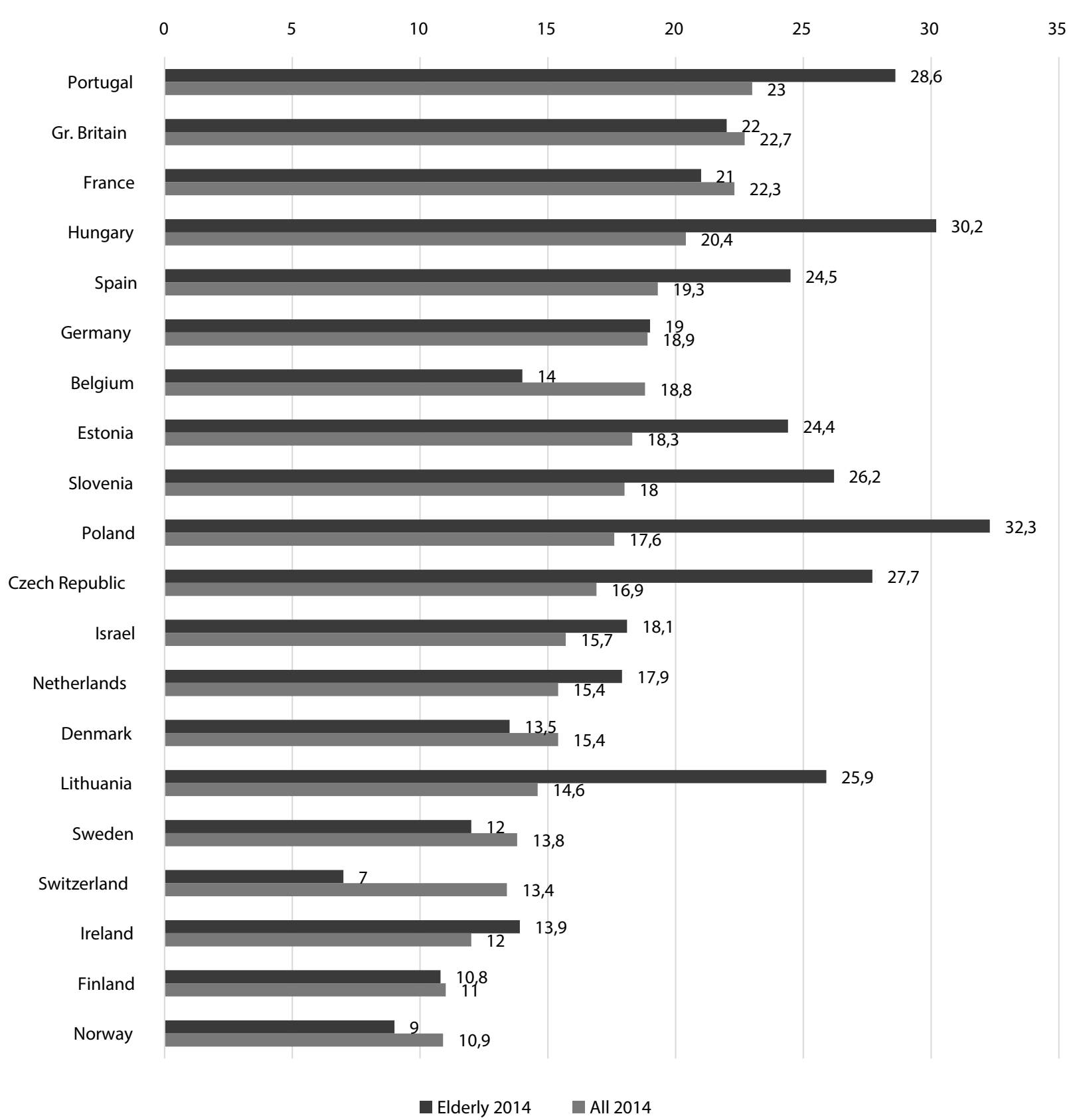

Figure 1. Percentage of people declaring sleep disorders in the adult population of European countries and those aged 65-80. Source: European Social Survey (ESS) 2014. Author's own calculations. 
place of old age in the hierarchy of the socially accepted values and the ties linking them to the rest of society, as these translate into the individual's quality of life and the mental comfort of everyday life.

The social inclusion of the younger generation may be regarded as one of the reasons for their well-being, whereas the social exclusion of the older generation has many consequences for their frame of mind. For this reason, the differences in the percentage of people experiencing sleeplessness in different countries in general and the differences between the results for whole populations and older people that are worth considering in the above summary. These are some of the indicators which enable the distance which separates older people from the rest of society to be evaluated. It is expected that older people have problems with their sleep more often than is observed in the whole population. Nevertheless, the patterns of the occurrence of sleeplessness in different countries are subject to differentiation and the distance separating old people from the rest of society indicates that not only biological factors are influential.

Three groups of countries, differing with respect to the occurrence of sleep disorders, can be observed. The first group includes those which are characterised by a relatively low percentage of people declaring sleep disorders (a frequency below the mean value for the surveyed countries $M=16.6 \%$ ) and by only small differences between the results for the whole population and for older people, which do not exceed more than plus or minus three percentage points. Thus, in these countries the quality of older people's sleep does not differ from the quality of sleep of the whole population, and in some cases it is even slightly better. This group includes Denmark, Sweden, Ireland, Finland, Norway, Israel, the Netherlands and Switzerland, where its older inhabitants sleep distinctly better. The second group comprises the countries in which the percentage of people complaining of sleeping badly is somewhat higher (above the mean value); however, as in the first group, the evaluation of the sleep of older people does not differ significantly from that of the total of the surveyed population, or is even better (Belgium). The third group is composed of the countries in which the percentage of those with sleep complaints is at the medium or higher levels, while at the same time considerable differences were found between the nationwide frequencies and the group of older people for whom the differences are significantly higher. Lithuania, the Czech Republic, Poland, Slovenia, Hungary, Spain and Portugal are in this group. It can be seen that this group contains all European countries with a socialist lineage. This suggests the influential role of the quality of life and specific experiences which older people encountered during the greater part of their life.

One of the important issues when interpreting the information on the spread of the occurrence of sleeplessness is the differences between men and women. The general observations, epidemiological data and the opinions of clinicians indicate that - as already stated - sleep disorders occur more often in women than men. At around the fifth decade of life, these differences are explained by biological changes in women, linked to the menopause, which are an acknowledged cause of their sleeplessness. When analysing the higher occurrence of sleep problems in women in the surveyed older age groups, it is explained by the demographic factor. Women, on average live longer, so more have a chance to experience sleeplessness, which then increases with age. These explanations, however, do not seem entirely satisfactory if the percentages of men and women in the same age group, in various countries, who complain of sleep disorders, are compared. They indicate the role of social and cultural factors which identify the two sexes in different places in the individual societies which, with other factors, may influence their frame of mind and consequently detract from peaceful sleep. The biggest differences between men and women in experiencing sleeplessness are found in Estonia, Lithuania and Poland (Figure 2), the countries of Eastern Europe, in which the status of men and women is defined in a traditionally patriarchal way.

However, it is significant that in the countries, where the relatively largest differences between the evaluations of sleep made by the total surveyed group and older people, and the differences between men and women (as in Poland), have been decreasing in recent years (Figure 3). This means that the third group of countries, depending on the percentage of those with sleep complaints in general, is approaching either the first or second group. This is undoubtedly a positive trend. It is illustrated by comparing the EES data from 2014 with those from 2006. The 2006 survey posed identical questions, although the lists of the countries participating in the two surveys did not correspond, however, comparable data are available for 17 countries.

Irrespective of the differences, for which the source can be sought in the socio-economic variables having a macro-social character, the most frequent reasons for insomnia at the individual level are psychological factors - mood disorders, in particular depression and the influence of psychosocial stresses. They may stem from the area of everyday life, family and professional life, or personal problems and setbacks. They may also derive from systemic variables which are translated into individual living conditions, the possibilities of functioning individually and well-being. Recognising the circumstances accompanying sleeplessness, or potentially contributing to experiencing it, is important for social policy initiatives directed at the improvement of the general quality of life of older people. The data collected by the European Social Survey enable such analyses to be made. It has to be remembered, however, that it was a survey of a general character, elucidating many diverse facts, phenomena or opinions. Therefore, using the results of such surveys imposes the quality of a secondary analysis of the research material. A fuller spectrum of data, which might contribute to the explanation of the frequency of the occurrence of sleeplessness, might be provided only by a study focused on this question. Using the data obtained from the 2014 EES survey, four groups of variables deserve attention from the point of view of the problem being considered in this paper: 


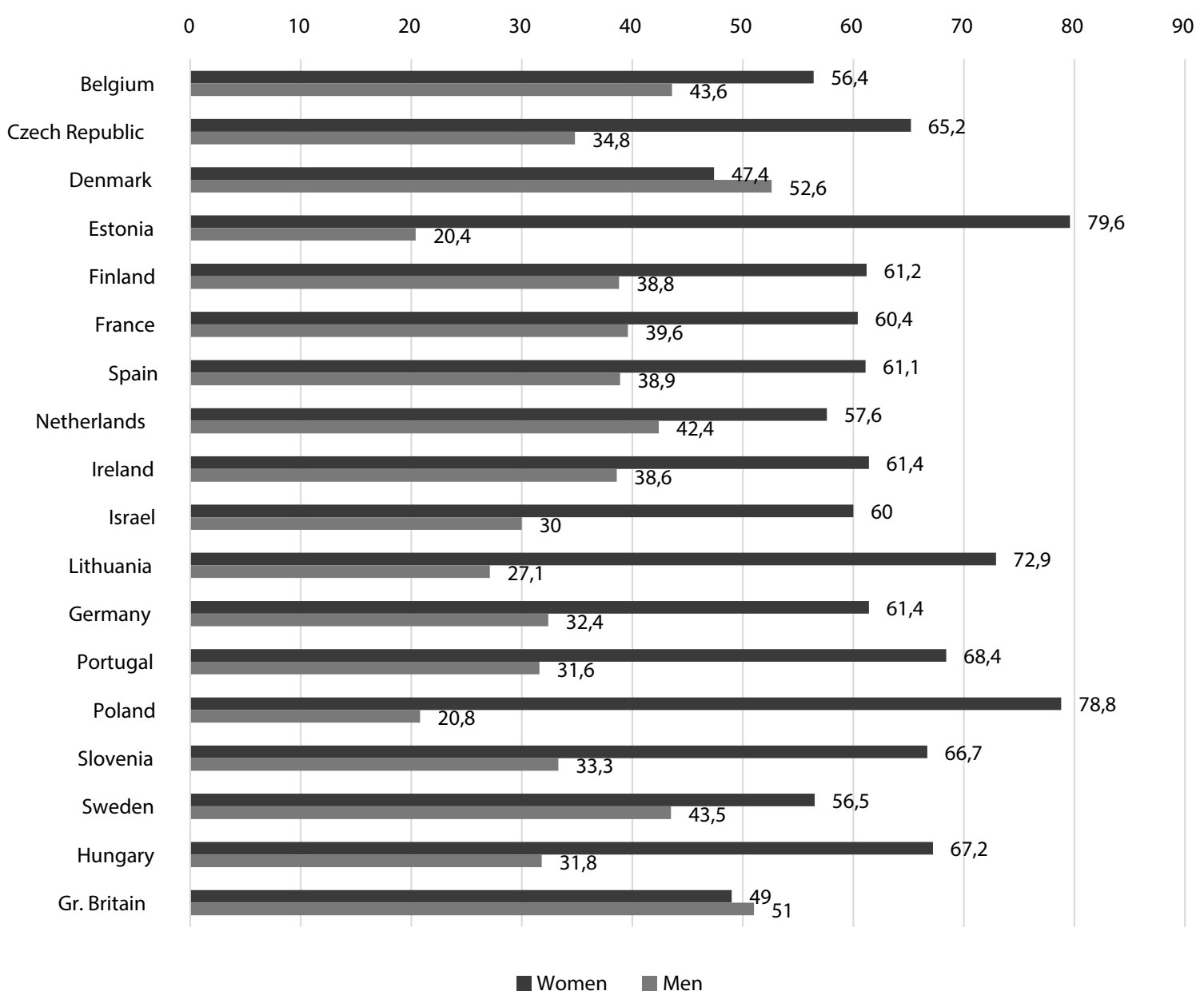

* Data for Switzerland and Norway have been excluded because of the small numbers of respondents in the indicated age categories.

Figure 2. Percentage of men and women aged 65-80 in European countries*, declaring sleep disorders.

Source: European Social Survey (ESS) 2014. Author's own calculations.

- the place in the social structure;

- evaluation of the state of health and behaviour related to health;

- frame of mind and satisfaction with life;

- relationships with others, the available support.

The above parameters identify the dissimilarity of life situations in the population of older people in different countries. It is known that their social situation, prosperity, state of health and satisfaction with life vary, which may, to a different degree, be linked to sleeplessness. In order to investigate the links between these indicators and the occurrence of sleeplessness among older people, the results of surveys from six selected European countries have been used. Three of them are those in which the frequency of sleeplessness among older people is close to that of the whole surveyed populations, Germany, France and the Netherlands. The other three countries, Poland, Estonia and the Czech Republic, are those in which considerable differences between the frequencies of sleep disorder have been recorded (see chart 1). The selection of these countries for further analyses was dictated by the numbers of people in the $65-80$ age brackets in the surveyed groups in the particular countries.
Consider the variables illustrating the place in the social structure. Their link with the occurrence of sleeplessness among older people, the explained variable, in the six analysed countries on the basis of logistic regressions is presented in Table I.

The results of the analysis indicate that the structural variables pertaining to the social situation do not play a significant role in the explanation of sleeplessness. The biggest role is played by gender, although the results vary from country to country. In Poland, compared to other countries, apart from the highest correlation between sleeplessness and gender, a statistically important impact of the unfavourable evaluation of the material situation, is evident, which is also apparent in Estonia and in the more well-to-do Netherlands. However, there is no evidence of a link between the level of education and size of the place of residence and complaints of sleeplessness in the six countries. In the above analysis, the differences of the impact of the social status on sleeplessness in the countries with larger or smaller variations in the frequency of declared sleep disorders between the whole populations and older people were not apparent. However, the issue deserves further analyses. 


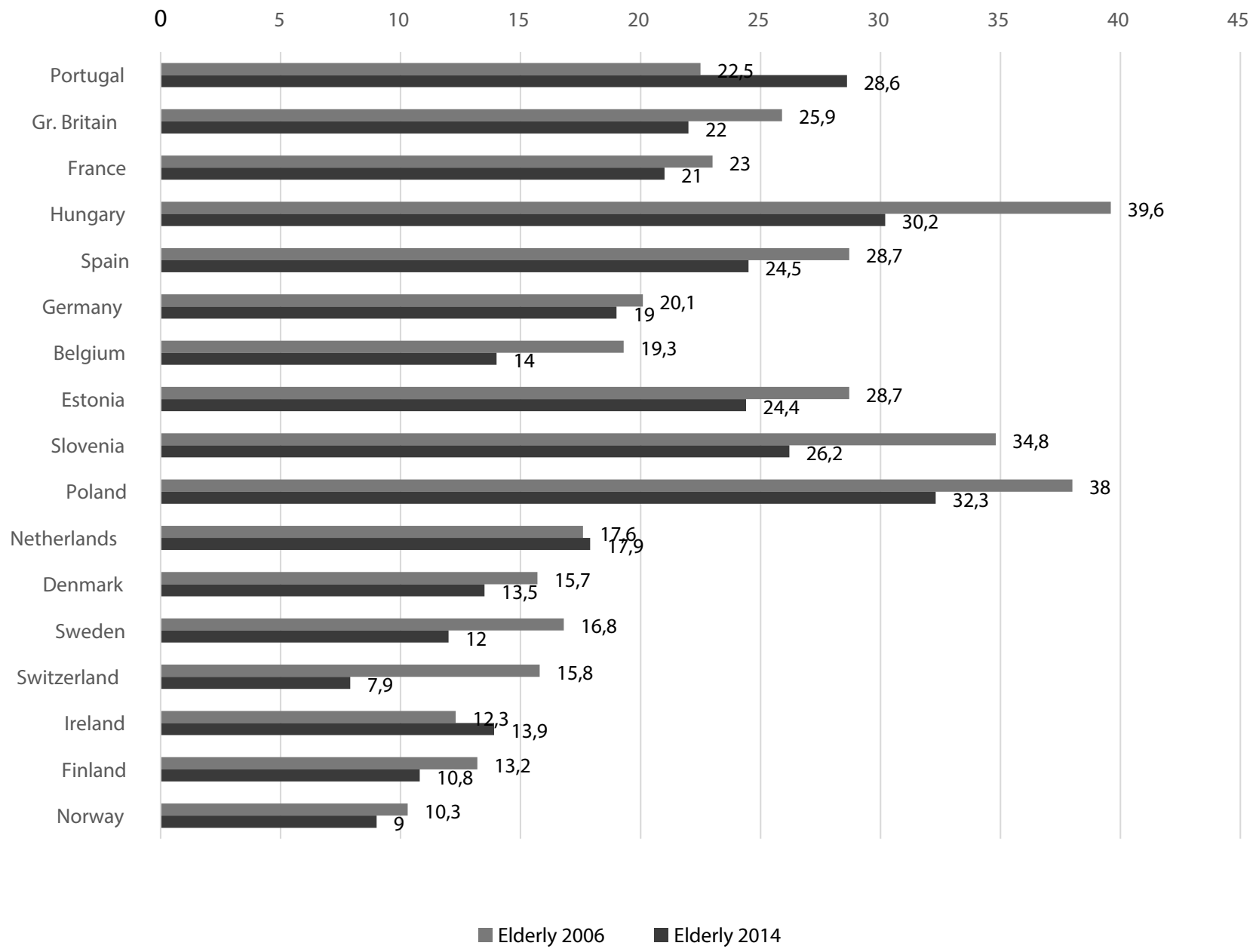

Figure 3. Percentage of people aged 65-80 in Europe declaring sleep disorders in 2006 and 2014.

Source: European Social Survey (ESS) 2006 and 2014. Author's own calculations.

\begin{tabular}{|l|c|c|c|c|c|c|}
\hline \multicolumn{1}{|c|}{ Predictors } & Germany & Netherlands & France & Poland & Czech Republic & Estonia \\
\hline $\begin{array}{l}\text { Gender } \\
\text { M }=0, \mathrm{~F}=1\end{array}$ & $2.57^{* * *}$ & $1.76^{*}$ & $2.04^{*}$ & $3.49^{* * *}$ & $1.84^{*}$ & $2.06^{* *}$ \\
\hline $\begin{array}{l}\text { Place of Residence } \\
\text { Big City = 1, } \\
\text { Small Village =5 }\end{array}$ & .99 & .91 & .94 & .91 & 1.00 & .96 \\
\hline $\begin{array}{l}\text { Education } \\
\text { ES - ISCED }\end{array}$ & .97 & 1.01 & 1.05 & .88 & 1.07 & .92 \\
\hline $\begin{array}{l}\text { Subj. Material Situation } \\
\text { Good, Affluent }=1 \\
\text { Bad =4 }\end{array}$ & 1.27 & $2.7^{* * *}$ & 1.55 & $1.65^{*}$ & 1.36 & $1.38^{*}$ \\
\hline
\end{tabular}

$* p<.05 ; * * p<.01 ; * * * p<.001$

Table I. Prevalence of sleep disorders by demographic variables and socio-economic positions in a logistic regression model. Six European countries, population aged 65-80.

Source: European Social Survey (ESS) 2014. Author's own calculations.

While structural variables can be treated as independent variables explaining the occurrence of sleeplessness, it does not apply to the remaining factors co-occurring with sleeplessness which have been identified. In the case of the variables linked with frame of mind, relationships with others and sometimes even with the evaluation of health, there is a possible two-way dependence. For example, an unhappy frame of mind can be the effect of sleeplessness as well as the cause. Recognising the nature of these relationships will show the syndromic character 
of the evaluations, feelings and moods accompanying sleeplessness in older people, and for the social practice, it will indicate the broader areas of influences to be directed at the improvement of these people's quality of life.

Table II shows the relationship between the variables referring to health and health awareness and the occurrence of sleeplessness. When calculating the coefficients of correlation a 1-4 scale of sleep disorders was used, where 1 signifies its non-existence and 4 - its occurrence during the whole, or almost the whole of the previous week.

In all countries the most important link is observed between the evaluations of the state of health and the occurrence of disability and sleep disorders. This interdependence is expected and totally obvious. Experiencing ailments, limitations, or worries about one's health, irrespective of the fact that problems with sleep may stem from the very character of the illnesses of old people, will contribute to the deterioration of sleep quality. Another measure of this relationship is the connection of sleep disorders with multi-morbidity, which is a number of declared chronic illnesses. The greater the number of such illnesses, the higher is the risk of sleeplessness. The illnesses most often mentioned in the analysed countries are: lumbar pain $-54.6 \%$, hypertension $-47.7 \%$, muscular and joints pain $-47.7 \%$, the cardiovascular system $-32.9 \%$, digestive problems $-25.9 \%$, breathing difficulties $-18.9 \%$, diabetes $-12.3 \%$.
The types of behaviour related to health, presented in the above table, do not distinguish between the studied countries according to the application of the principles of a health-promoting life style, treated here as an expression of active health awareness and the recognition of the individual's ability to influence it. They have no significant relationship to sleeplessness; apart from physical exercise, which is rather low in the case of older people, and is lacking in the four countries linked with the highest occurrence of sleep disorders. It has to be added that the questions regarding physical exercise in the EES survey, in addition to participation in a sport, also focused on its moderate forms - faster walking and any form of exercise for a minimum of 30 minutes. The link between the lack of physical exercise and sleeplessness is relatively greater in Estonia and in Poland.

Within the framework of health related behaviour of the surveyed population, the use of health care services - seeing GPs and specialists and the difficulties of obtaining such care - has been taken into consideration. There is no evidence that consulting doctors was directly linked to the sleeplessness analysed here and the field of the specialists, such as seeking help from psychiatrists dealing with sleeplessness, is not known. However, it may be assumed, that irrespective of the reason for the appointments - contacting a doctor and remaining in his or her care, apart from getting immediate advice, has a positive impact on the older person's sense of health security.

\begin{tabular}{|c|c|c|c|c|c|c|}
\hline & Germany & Netherlands & France & Poland & $\begin{array}{c}\text { Czech } \\
\text { Republic }\end{array}$ & Estonia \\
\hline $\begin{array}{l}\text { Health: Health status evaluation } \\
1 \text { - very good, } 5 \text { - very bad }\end{array}$ & $.29 * * *$ & $.37 * * *$ & $.25 * * *$ & $.30 * * *$ & $.29 * * *$ & $.26^{* * *}$ \\
\hline Disability: 1 -not, 3 -severe & $.21 * * *$ & $.40 * * *$ & $.17 * *$ & $.29 * * *$ & $.29 * * *$ & $.24 * * *$ \\
\hline $\begin{array}{l}\text { Number of chronic diseases: } \\
\qquad 1-8 \text { diseases }\end{array}$ & $.30 * * *$ & $.17 * * *$ & $.30 * * *$ & $.28 * * *$ & $.26 * * *$ & bd. \\
\hline $\begin{array}{c}\text { Contacts with physicians: Visiting GP, } \\
\text { last year } \\
1-\text { yes, } 0-\text { no }\end{array}$ & $.12 * *$ & .1 & -.04 & 0.08 & -.07 & $.15 * *$ \\
\hline $\begin{array}{l}\text { Visiting specialist, last year } \\
1-\text { yes, } 0-\text { no }\end{array}$ & $.11 * *$ & $.17 * *$ & .09 & 0.08 & $.20 * * *$ & $.14 * *$ \\
\hline $\begin{array}{l}\text { Trouble in getting to a doctor } \\
\qquad 1-\text { yes, } 2-\text { no }\end{array}$ & -.03 & $-.21 * * *$ & -.04 & $-.18 * *$ & .02 & -.04 \\
\hline $\begin{array}{l}\text { Health related behaviour: Eating fruit } \\
1 \text { - several a day, } 7 \text { - not at all }\end{array}$ & 0 & -.02 & -.03 & -.010 & -.03 & 0 \\
\hline $\begin{array}{c}\text { Eating vegetables } \\
1-\text { several times a day, } 7-\text { not at all }\end{array}$ & .02 & .02 & .08 & -.037 & .01 & \\
\hline $\begin{array}{c}\text { Physical activity (last week) } \\
1-\text { no, } 7 \text { - every day }\end{array}$ & $-.11 * *$ & $-.13 * *$ & -.06 & $-.16^{* *}$ & -10 & $-.21 * * *$ \\
\hline $\begin{array}{l}\text { Smoking } \\
1 \text { - every day, } 5 \text { - never }\end{array}$ & .08 & .03 & .02 & .05 & -.05 & .05 \\
\hline
\end{tabular}

$* p<.05 ; * * p<.01 ; * * * p<.001$

Table II. Correlations between reported sleep disorders and selected indicators of health and health related behaviour for six European countries (Pearson's r).

Source: European Social Survey (ESS) 2014. Author's own calculations. 
The lack of the necessary access to a doctor in two of the analysed countries, the Netherlands and Poland, remains crucially linked to the occurrence of insomnia, which can be a manifestation of an unappeased worry about health and a source of anxiety about the lack of the required health care. There are distinct differences between the use made of GP's and specialist care in the individual countries. These differences suggest that health care for older people in Germany and Estonia is undertaken by both GPs and specialists, but more by specialists in the Netherlands and the Czech Republic; in Poland and France no distinct pattern is apparent. The situation may to some degree be influenced by the patients' individual preference, but it is determined largely by the accessibility to doctors offered by the health care system applied in the particular country.

Another aspect to be taken into consideration in its relationship to sleeplessness is the individual's frame of mind and satisfaction with life. Negative feelings in this respect - according to expectations - often accompany sleeplessness and are of essential importance for defining the context in which sleeplessness occurs. It is illustrated by the results presented in Table III.

In all countries the occurrence of sleep disorders is most strongly linked to feelings of despondency, discouragement, sorrow and the inability to enjoy life. These can all be associated with a depressive disposition and a generally low satisfaction with life, for which there can be other causes. However, comparing the frequency of sleep disorders with declarations of feelings of depression and discouragement, which according to the ICD-10 classification is one of the basic symptoms considered when diagnosing depression, indicates that complaints of insomnia are significantly more frequent in the surveyed age group in all the analysed countries than depressive states, which are an independent source of the problem. The percentage differences are respectively: Germany 15.0; the Netherlands - 13.6; France - 14.6; Poland 12.6; the Czech Republic - 8.0, and Estonia - 15.7. This indicates the legitimacy of considering sleep disorder as a separate and independent phenomenon. Overall, all the above conditions are indicators of a lowered sense of well-being, which have a bearing on activity, the possibility of social functioning and the general quality of life of older people. The accompanying feeling of weariness and lack of energy may be an indicator of physical strength decreasing with age, or the result of the experienced somatic conditions and disability.

France differs slightly from the general pattern because the level of satisfaction and enjoyment of life has the smallest relative impact on the quality of sleep. One may wonder whether it stems from a certain cultural specificity, stereotypes, of the French, who tend to look for joie de vivre, even in situations which are not generally optimistic. Poland, when compared with other countries, is distinguished by a high intensity of sadness and depression, coexisting with sleep disorders, and a relatively high level of weariness and a generally low satisfaction with life, which also influences sleep quality. It is noteworthy that compared to the citizens of other countries the satisfaction with life of older Poles is at a lower level than those in other countries. Grading satisfaction with life on a scale of $0-10$, gives an average for $18 \mathrm{Eu}-$ ropean countries of $\mathrm{M}=7.40$, but for Poland $\mathrm{M}=6.66$.

Other factors, essential for a person's functioning and well-being, are their relationships with other people, their social ties and sources of support on which they may count from their nearest and less close milieu. Satisfying relationships with others are indicated by several researchers (see the review in [23]) as being an important element of the social capital and a vital resource for coping efficiently with life's problems and difficulties. Therefore, it is worth asking to what extent it is a significant resource for securing quiet sleep. The dependences between the indicators of the relationships with other people and the occurrence of sleep are given in Table IV.

What is extremely significant is the acute sense of loneliness experienced or encountered by older people in the surveyed countries, which is relatively most strongly correlated with the experience of sleeplessness. The high-

\begin{tabular}{|c|c|c|c|c|c|c|}
\hline & Germany & Netherlands & France & Poland & Czech Republic & Estonia \\
\hline $\begin{array}{l}\text { Life satisfaction } \\
0-10\end{array}$ & $-.19 * * *$ & $-.30 * * *$ & -.07 & $-.31 * * *$ & $-.27 * * *$ & $-.16^{* * *}$ \\
\hline $\begin{array}{l}\text { Joy of life } \\
0-10\end{array}$ & $-.28 * * *$ & $-.32 * * *$ & $-.16^{*}$ & $-.27 * * *$ & $-.18 * * *$ & $-.23 * * *$ \\
\hline $\begin{array}{c}\text { Reduced energy } \\
1-\text { no, } 4-\text { all the time }\end{array}$ & $.31 * * *$ & $.35 * * *$ & $.30 * * *$ & $.37 * * *$ & $.32 * * *$ & $32 * * *$ \\
\hline $\begin{array}{c}\text { Depressed mood } \\
1-\text { no, } 4-\text { all the time }\end{array}$ & $.27 * * *$ & $.46 * * *$ & $.33 * * *$ & $.47 * * *$ & $.36^{* *}$ & $.42 * * *$ \\
\hline $\begin{array}{c}\text { Feeling of sadness } \\
1-\text { no, } 4 \text { - all the time }\end{array}$ & $.16^{* * *}$ & $.15 * * *$ & $.30 * * *$ & $.43 * * *$ & $.35 * * *$ & $.37 * * *$ \\
\hline
\end{tabular}

$* p<.05 ; * * p<.01 ; * * * p<.001$

Table III. Correlations between reported sleep disturbances with the frame of mind and the satisfaction with life (Pearson's r). Source: European Social Survey (ESS) 2014. Author's own calculations. 


\begin{tabular}{|c|c|c|c|c|c|c|}
\hline & Germany & Netherlands & France & Poland & $\begin{array}{c}\text { Czech } \\
\text { Republic }\end{array}$ & Estonia \\
\hline $\begin{array}{c}\text { Confidence in people } \\
0-10\end{array}$ & $-.11^{* *}$ & $-.15^{* *}$ & 0.02 & $-21^{* * *}$ & $-13^{*}$ & $-.10^{*}$ \\
\hline $\begin{array}{c}\text { Feeling of safety in place of } \\
\text { residence } \\
1-4\end{array}$ & $-.13^{* * *}$ & $-.18^{* * *}$ & $-.15^{*}$ & -.04 & $-.15^{* *}$ & $-.16^{* * *}$ \\
\hline $\begin{array}{c}\text { Contacts with friends or relatives } \\
1-\text { no, } 7-\text { every day }\end{array}$ & -.07 & -.07 & .07 & -.04 & -.08 & -.06 \\
\hline $\begin{array}{c}\text { Number of close, trusted people } \\
0-6\end{array}$ & -.03 & $-.14^{* *}$ & .04 & $-.19^{* *}$ & -.05 & $-.11^{*}$ \\
\hline $\begin{array}{c}\text { Participation in religious activities } \\
1-\text { every day, } 7-\text { never }\end{array}$ & -.01 & .02 & -.05 & .08 & 0.01 & -.06 \\
\hline $\begin{array}{c}\text { Feeling lonely } \\
1-\text { no, } 4-\text { all the time }\end{array}$ & $.11^{* *}$ & $.29^{* * *}$ & $.19 * *$ & $.29 * * *$ & $.32^{* * *}$ & $.23^{* * *}$ \\
\hline $\begin{array}{c}\text { Living in a single household } \\
0-1\end{array}$ & 0.03 & $.10^{*}$ & .07 & .06 & .07 & .03 \\
\hline $\begin{array}{c}\text { Feeling of discrimination of elderly } \\
0-1\end{array}$ & 0.04 & 0.05 & -.04 & .09 & .08 & -.02 \\
\hline
\end{tabular}

$* p<.05 ; * * p<.01 ; * * * p<.001$

Table IV. Correlation of sleep disorder and the relationships with other people (Pearson's $r$ ).

Source: European Social Survey (ESS) 2014. Author's own calculations.

est dependence is observed in the Netherlands, Poland and the Czech Republic. It is worth pointing out, however, that it is a statement of subjective feelings; no relationship between sleeplessness and living alone in a one person household has been observed. High dependence is also noted between sleep complaints and a low degree of general trust in people, the conviction that people try to use, rather than help, one another and the feeling of being safe in the place of residence. In both cases of having these feelings, fear can be detected, danger arising from an interaction with other people. It is worth adding that significantly higher coefficients of the correlation between sleeplessness and the lack of trust in others are linked to the little trust in people felt generally, as in Poland. The average level of trust on the $0-10$ scale in 15 European countries is $M=5.42$, but in Poland $M=3.92$.

Despite the clear link between sleeplessness and the sense of loneliness, the frequency of contacts with acquaintances or relatives is proven to be non-essential. Perhaps such conventional meetings are not capable of safeguarding older people from the feeling of loneliness, which is so clearly linked to sleeplessness.

The fact of having close, more intimate contacts with people they trust does not appear to be generally advantageous. However, the lack of such people does seem to be significant in the Netherlands, Poland and, to a lesser degree, in Estonia. In none of the surveyed countries is the impact of participation in religious life visible in the table of results. However, it might be considered - apart from the aspects of faith - as participating in a community that could be a source of support and backing in difficult situations.
No relationship between sleep disorders and the sense of deprivation or discrimination against older people, i.e. having feelings linking one's personal situation with macro-social factors, was observed in any of the countries.

\section{Concluding remarks}

Of the status variables only gender and the evaluation of one's material situation are good predictors of sleeplessness, although it varies in the individual countries. As far as gender is involved the clearest differences in achieving a good quality of sleep by men and women was observed in Poland, to the disadvantage of women. In addition, the evaluation of the material situation has a significant impact on the quality of sleep in Poland and Estonia - and interestingly, in the more affluent Netherlands. However, it has to be remembered that subjective evaluations have been considered. Neither the level of education, nor the size of the location of residence of the respondents was of substantial importance in any country. Thus, on the whole, the role of the variables linked to the social status - apart from gender - is not significant for explaining the phenomenon of sleeplessness; however, the influence of gender includes both biological and social components.

Factors related to the state of health obviously provide a considerably clearer link to the occurrence of sleep disorders. The analysis highlighted three issues. These were the variables concerning the evaluation of the state of health, the use of medical care and pro-health behaviour. The strongest interdependences were observed between the general evaluation of the state of health; 
disability, causing difficulties with everyday actions resulting from a long illness; functional limitations; some afflictions or problems of a psychological nature and multi-morbidity. These dependences are high in all the surveyed countries. While the patterns of contacts with doctors indicate a different approach to using health services in the individual countries - GPs or specialists, the perceived difficulties of access to doctors, irrespective of their specialisation, have a psychological dimension. This may constitute an important source of discomfort which is important for the general well-being and quiet sleep. This indicates the vital role of GPs and the need to improve the level of their knowledge and make them aware of the importance of the psychological problems of older people.

Interdependences between the perceived accessibility to doctors and the frame of mind of older people are statistically significant in Poland and the Netherlands, although one may predict that the objective accessibility of health care for older people is not similar in the two countries. It may be recalled that both Dutch and Polish respondents indicated the important influence of an unfavourable evaluation of their material situation on their ability to achieve quiet sleep. There could be an assumption that the coincidence lies in the different subjective expectations of the level of satisfaction with the various aspects of life in each country.

The variables illustrating pro-health behaviour are a general indicator of older people caring actively for their health and one should not have expected a particularly high dependence between the patterns of diet (as in Table II) and difficulties with sleeping. However, its existence cannot be excluded, especially with regard to the consumption of coffee and/or alcohol. In total, they show that apart from physical exercise, factors of a prohealth lifestyle are statistically of no significance. The role of low physical activity is, nevertheless, visible and it is particularly important in Estonia. However, it is not possible to define the direction of this dependence; low physical activity may be both the cause and the effect of the state of health influencing the quality of sleep or contribute to sleeplessness.

An unfavourable psychological state, which is the lot of many older people, was shown to be the most important factor co-occurring with sleep disorders. Irrespective of the country, although with a different intensity, it correlates positively with sleeplessness and at a higher level than those indicated between the variables related to somatic health and sleeplessness. It is clearly visible when feelings such as discouragement and depression, weariness and lack of energy exist. In Poland, compared to other countries, the highest dependences between the experience of sleeplessness and the feeling of depression, discouragement and sadness and a generally low satisfaction with life are indicated. The pessimism, particularly of older Poles, its sources and consequences undoubtedly requires deeper analysis.

Sleeplessness and a poor psychological state in older people are often accompanied by unfavourable phenomena related to their social interactions and the feelings that are induced. They constitute an important factor for the general quality of life. Primarily, in all countries, it is the feeling of loneliness which has a critical relationship to sleeplessness. Even when a totally satisfying level of contact with family and friend is lacking, it is the absence of really close trusted people, who can be relied on as a source of support and shelter in difficult times, rather than having to cope alone, which causes loss of sleep, which is more apparent.

The contact with close, trusted people is not ensured by living with a spouse or other members of the family. Apart from the Netherlands, although marginally $p<.05$, living alone in a one person household does not intensify the subjective feeling of loneliness, which is a significant cause of poor sleep quality. This can be generalised as the quality of the psychological frame of mind. It is accompanied by little physical activity in the surveyed group of older people, possibly limiting them leaving their house - which could have the effect of reducing their interpersonal contacts.

In addition, those who sleep poorly are characterised by some negative attitudes towards people in general. These attitudes may result from their own experiences, or preconceptions which emphasise the dangers lurking for older people. They may be linked to the experience of violence towards old people, or the fear of it. However, they assume a slightly different character in the surveyed countries. In Poland little trust in people, together with the relatively smallest sense of fear and danger related to one's neighbours is apparent. However, a limited sense of safety in the neighbourhood is a painful problem felt by older people in the other countries. Despite the experience of various difficulties - material, health or those connected with the social isolation they feel - older people do not feel discriminated against because of their age in any of the surveyed countries, at least not to any degree which would have an impact on their lowered mood or their quality of sleep.

The leading variable in all the analyses is the sleep difficulties of older people. From the presented pattern of dependences, it is very apparent that it is not an isolated phenomenon, which is in itself a problem. If this was the case, it could be assumed that a good solution would be simply a safe, non-addictive pharmacological product. However, the phenomenon of sleeplessness among older people is an element of a syndrome to which several other factors inducing an unfavourable psychological state and limited social functioning contribute. They accumulate and augment one another, thereby lowering the quality of life and the social exclusion of these people. Only certain features of this syndrome can be considered, as the European Social Survey, which was the basis of the analyses conducted here, was not a survey aimed at a deep analysis of the phenomena of sleep disorders. For instance, the family situation and its supportive potential, relations with the world of help institutions, cognitive activity, the available sources of satisfaction and a number of other spheres of life improving or limiting its comfort have not been considered. Additionally, the main variable - sleeplessness - was not conceptualised in a perceptive 
way. It is not known to what extent the reported sleep disorders had a chronic character. Nevertheless, the available data and analyses undoubtedly indicate that actions focused on improving the life of older people, to secure a better quality of sleep, should be directed at the whole complexity of their mutually conditioning life situation, for which a sociological analysis could contribute several new elements.

\section{Health promotion perspective}

What practical recommendations for social and health policies directed at the quality of life and functioning of old people may follow from the above analyses? From the point of view of socio-economic systemic actions, the important requirement is providing older people with proper material security and the availability of medical services, especially in those countries in which their lack is a source of distinct discomfort. This need applies primarily to women for whom entering old age causes a clearer deterioration of their material situation than it does for men.

Such actions require changes in the whole social and economic policy and are conditioned by both the economic situation and ideological-axiological premises concerning the principles of social equality. Apart from macro-social actions, it is possible to indicate several initiatives which can be carried out at the level of local milieus which do not require major-systemic transformations. These are actions to stimulate older people, increase their social integration and their sense of safety, prevent loneliness and isolation and promote health. However, it is not only a question of creating specialised institutions, although undoubtedly they are needed - for instance universities of the third age, but of enhancing the motivation and competences of older people so that they can participate. It also implies building health competences; with advancing age, especially among people of a lower social status, the ability to obtain and understand information relating to health and illness decreases, forcing them to rely on doctors and medication, or gives them a sense of needs deprivation. Therefore, there is undoubtedly a need for special health education and the promotion of health aimed at the needs of older people and the possibilities of making use of them - and it is health promotion in a broad sense that is needed not disease prevention. Reference to good practices with proven efficiency verified by experts in different countries may be helpful [24]. From the point of view of the topic under discussion, initiatives related to the promotion of mental health and help with overcoming depressing solitude would be particularly valuable. Social isolation fosters a multitude of unfavourable phenomena - a higher susceptibility to stress and anxiety, difficulties adapting to changes, neglect of needs, risk of becoming a victim of violence and -as it has been shown - experiencing sleeplessness. Therefore, for seniors, a need exists to develop individual abilities to cope with difficult life situations and to create conditions which enhance the use of these abilities. Among them is the shaping of environments, so as to make them conducive to the fulfilment of needs and the life goals of older people, strengthening their social ties and a satisfying lifestyle, one which is as active as possible. The role of the media cannot be overestimated, as they have the opportunity to transform the negative stereotypes of old age and older people in the social consciousness and to build positive social attitudes towards them. All these actions will be helpful in creating foundations for active, modern ageing, maintaining the sense of value and psychosocial well-being of older people and consequently their better quality of sleep.

\section{Note}

1 The criteria of chronic insomnia are not uniform: some researchers define it as lasting longer than a month [2], others point to the period of permanent disorders during 3 weeks or occurring roughly for a period of a month [3].

\section{References}

1. Broczek K., Mossakowska M., Szybalska, A., Kozak-Szkopek E., Wieczorowska-Tobis K., Parnowski T., Występowanie objawów depresyjnych u osób starszych, in: Mossakowska M., Więcek A., Błędowski P. (eds.), Aspekty medyczne, psychologiczne, socjologiczne i ekonomiczne starzenia się ludzi w Polsce, terMedia, Poznań 2012.

2. Szelenberger W., Standardy leczenia bezsenności Polskiego Towarzystwa Badań nad Snem, "Farmakoterapia w Psychiatrii i Neurologii”, Warszawa 2003; 1: 5-16.

3. Roth T., State of the Science Conference on Manifestation and Management of Chronic Insomnia in Adults, "Sleep" 2005, "National Institute of Health" 2005: 1049-1057.

4. Korzeniowski L., Pużyński S. (eds.), Bezsenność, in: Encyklopedyczny stownik psychiatrii, PZWL, Warszawa 1986.

5. Hauri P.J., Case Studies in Insomnia, Plenum Medical Book Co, New York 1991.

6. Simon G.E., Van Korff M., Prevalence, burden and treatment of insomnia in primary care, "American Journal of Psychiatry” 1997; 154: 1417-1423.

7. Samochowiec A., Konopka A., Kobiety a uzależnienia, in: Ostrowska A. (ed.), Raport Polki 2013, Fundacja MSD dla zdrowia kobiet, Warszawa 2013.

8. Kales A., Kales J.D., Evaluation and Treatment of Insomnia, Oxford University Press, New York 1984.

9. Jeffers M., Cultural aspects of ageing: Gender and intergenerational issues, "Social Sciences and Medicine" 1996; 43 (5): 681-688.

10. Arber S., Davidson K., Ginn J., Changing approaches to gender and later life, in: Arber S., Davidson K., Ginn J. (eds.), Gender and Ageing. Changing Roles and Relationships, Open University Press, Maidenhead 2003.

11. Ohayon M., Epidemiology of insomnia: What we know and what we still need to learn, "Sleep Medicine Review" 2002; 6 (2): 97-111.

12. Tobiasz- Adamczyk B., Brzyski P., Bajka J., Społeczne uwarunkowania jakości życia kobiet u progu starszego wieku, Wydawnictwo Uniwersytetu Jagiellońskiego, Kraków 2004.

13. Mossakowska M., Więcek A., Błędowski P., Aspekty medyczne, psychologiczne socjologiczne i ekonomiczne starzenia się ludzi w Polsce, terMedia, Poznań 2012. 
14. Breslau N., Rosenthal L., Roth T., Andreski P., Sleep disturbance and psychiatric disorders: A longitudinal epidemiological study, "Biological Psychiatry" 1996; 39: 411-418.

15. Kiejna A., Wojtyniak B., Rymaszewska J., Stokwiszewski J., Prevalence of insomnia in Poland - results of National Health Interview Survey, "Acta Neuropsychiatrica" 2003; 15: 68-73.

16. Central Statistical Office, Stan zdrowia ludności Polski w 2009 roku, Warszawa 2011.

17. Ford D.E., Cooper-Patrick L., Sleep disturbances and mood disorders - an epidemiologic perspective, "Depression and Anxiety" 2001; 14: 3-6.

18. Moskalewicz J., Kiejna A., Wojtyniak B., Kondycja psychiczna mieszkańców Polski, Instytut Psychiatrii i Neurologii, Warszawa 2012.

19. Klemmack D.L., Roff L.L., Fear of personal ageing and subjective wellbeing in later life, "Journal of Gerontology" 1984; 39: 756-775.

20. Borsch-Supan A., Survey of Health, Ageing and Retirement in Europe (50+ in Europe), wave 5, Munich 2016. doi:10.6103/SHARE w5.600.
21. Hyyppa M.T., Kronholm E., Alanen E., Quality of sleep during the economic recession in Finland: A longitudinal cohort study, "Social Science and Medicine" 1997; 45 (3): 731-738.

22. Arber S., Gender, marital status and sleep problems in Britain, "Przeglad Lekarski" 2012; 69 (2): 54-60.

23. Ostrowska A., Styl życia a zdrowie, Wydawnictwo IFiS PAN, Warszawa 1999.

24. Golinowska S., Promocja zdrowia dla osób starszych, Wydawnictwo Naukowe Scholar, Warszawa 2017.

\section{Data Soulces}

25. European Social Survey (2014); http://europeansocialsurvey.org/data and: www.ifispan.pl European Social Survey - ESS results (accessed: 20.02.2017).

26. Eurostat (2016); http://europa.eu./eurostat/statistics-explained/index.php/File:Life_expectancy_at birth_1980_ 2014_(years)_YB16.png (accessed: 16.04.2017).

Przygotowanie do wydania elektronicznego publikacji-zadanie finansowane w ramach umowy Nr 780/P-DUN/2017 ze środków Ministra Nauki i Szkolnictwa Wyższego przeznaczonych na działalność upowszechniająca naukę. 